\title{
On central bank interventions and transaction taxes
}

Frank H. Westerhoff

University of Osnabrueck

Department of Economics

Rolandstrasse 8

D-49069 Osnabrueck

Germany

Email: frank.westerhoff@uos.de

\begin{abstract}
We show that carefully designed central bank interventions may have a similar (stabilizing) effect on foreign exchange dynamics as transaction taxes. Transaction taxes seek to curb speculative activity. If speculators consist of chartists and fundamentalists - as indicated by many empirical studies - central banks may seek to replicate the impact of transaction taxes by countering the orders of these traders. This would simultaneously require trading against the current exchange rate trend and, surprisingly, slowing down the convergence of the exchange rate towards its fundamental value.
\end{abstract}

\section{JEL classification}

E58, F31, G14, G18

\section{Keywords}

foreign exchange markets, technical and fundamental analysis, central bank interventions, transaction tax 


\section{Introduction}

Empirical evidence reveals that professional market participants apply both technical and fundamental analysis to determine their orders (Allen and Taylor 1990, Taylor and Allen 1992, Lui and Mole 1998). While technical trading rules aim at exploiting persistent price trends, fundamental analysis assumes that prices will converge toward their fundamental values. Theoretical evidence points out that the interplay between chartists and fundamentalists may stimulate exchange rate fluctuations. For instance, models by Day and Huang (1990), Brock and Hommes (1998), Lux and Marchesi (2000), Rosser, Ahmed, and Hartmann (2003), de Grauwe and Grimaldi (2006) or Chiarella, Dieci and He (2006) are able to mimic some important stylized facts of financial markets (such as fat tails or volatility clustering). This literature is in line with the view that financial markets are excessively volatile and may display severe bubbles and crashes.

Already Keynes (1936), and later also Tobin (1978), suggested to impose transaction taxes in order to placate financial market dynamics. While there is some new theoretical reasoning that transaction taxes may indeed stabilize financial markets (Westerhoff 2004, Westerhoff and Dieci 2006), Garber and Taylor (1995) argue that it is more or less impossible to impose a Tobin tax in practice. Besides several technical considerations, there is also the fear that market liquidity may sharply decline. A general survey of this topic is provided by Haq, Kaul, and Grunberg (1996).

The goal of this paper is to explore whether the effect of transaction taxes may be replicated by carefully designed central bank interventions. Inspired by the empirical and theoretical literature mentioned above, we develop a simple model with chartists and fundamentalists in which the exchange rate evolves according to a second-order linear difference equation. For some parameter combinations, the model produces a cyclical behavior of the exchange rate with decreasing amplitude. As previously shown by Westerhoff 
(2004), transaction taxes may have a stabilizing impact on the dynamics even if the trading activity of both stabilizing fundamentalists and destabilizing chartists declines. The intervention behavior of central banks is discussed in-depth by Neely (2001) and Sarno and Taylor (2001). Central banks typically intervene in the direction of the fundamental value or counter the current exchange rate trend. ${ }^{1}$ In doing so, they reinforce the activity of fundamentalists or weaken the impact of chartists. Although it may appear odd at first sight, we show that replicating the effect of transaction taxes requires offsetting the orders of both fundamentalists and chartists. With the central bank as an additional player, market liquidity may even increase.

We continue as follows. In section 2 , we present a simple linear exchange rate model with chartists and fundamentalists to study first the working of transaction taxes. In section 3, the same model is used to investigate the consequences of some central bank intervention strategies. The last section offers some conclusions.

\section{A simple exchange rate model with transaction taxes}

The exchange rate is determined on an order-driven market according to a log-linear price adjustment function. The log exchange rate $P$ in period $\mathrm{t}+1$ is given as

$P_{t+1}=P_{t}+a\left(D_{t}^{C}+D_{t}^{F}\right)$

where $a$ is a positive price adjustment parameter. The orders of chartists and fundamentalists are denoted by $D^{C}$ and $D^{F}$, respectively. According to (1), excess buying drives the exchange rate up and excess selling drives it down.

\footnotetext{
${ }^{1}$ Taylor (2004), using actual intervention data, shows that central bank interventions may have a stabilizing effect on the foreign exchange market when it is dominated by noise traders.
} 
Fundamental analysis predicts that the exchange rate will return towards its fundamental value. Fundamental trading rules therefore suggests buying (selling) when the exchange rate is below (above) its fundamental value. Let $F$ be the log of the fundamental value. Then the orders of the fundamentalists may be formalized as

$D_{t}^{F}=\frac{b}{1+\operatorname{tax}}\left(F-P_{t}\right)$

The first term of the right-hand side of (2) captures the aggressiveness of fundamental traders. $b$ stands for a positive reaction coefficient and $\operatorname{tax} \geq 0$ is the imposed transaction tax. Obviously, fundamentalists trade less forcefully when the tax rate increases.

Technical analysis seeks to derive trading signals out of past price movements. Technical traders typically submit buying (selling) orders when the exchange rate increases (decreases). Their orders may be expressed as

$D_{t}^{C}=\frac{c}{1+\operatorname{tax}}\left(P_{t}-P_{t-1}\right)$

The aggressiveness of technical traders depends on the reaction coefficient $c>0$ and on the imposed transaction tax. The larger the levy, the weaker the influence of the chartists.

Without loss of generality, we can set $a=1$. Combining (1)-(3) yields the law of motion of the exchange rate

$$
P_{t+1}+\left(\frac{b}{1+\operatorname{tax}}-\frac{c}{1+\operatorname{tax}}-1\right) P_{t}+\frac{c}{1+\operatorname{tax}} P_{t-1}=\frac{b}{1+\operatorname{tax}} F
$$

which is a second-order linear difference equation.

Remember that the fixed point of a second-order linear difference equation $S_{t+1}+a_{1} S_{t}+a_{2} S_{t-1}=A$ is given as $S_{t}=A /\left(1+a_{1}+a_{2}\right)$. The fixed point is stable if the conditions $1+a_{1}+a_{2}>0,1-a_{1}+a_{2}>0$, and $1-a_{2}>0$ hold. Cycles are observed for 
$4 a_{2}>a_{1}^{2}$. In the case of dampened oscillations, a decrease of $a_{2}$ always yields a lower amplitude (Baumol 1961).

The following results are derived in Westerhoff (2004). The fixed point of the model, given as $P_{t}=F$, is independent of transaction taxes. The fixed point is stable if $b /(1+\operatorname{tax})>0, \quad b<2+2 \operatorname{tax}+2 c$, and $c<1+\operatorname{tax}$. Hence, transaction taxes enlarge the parameter space in which the trajectory of the exchange rate does not explode. Since $a_{2}=c /(1+\operatorname{tax})$, imposing a transaction tax decreases the amplitude of cycles. These occur for $c+(1+\operatorname{tax})-2 \sqrt{c(1+\operatorname{tax})}<b<c+(1+\operatorname{tax})+2 \sqrt{c(1+\operatorname{tax})}$. Overall, one may conclude that transaction taxes have some potential in stabilizing exchange rate fluctuations.

\section{The model with central bank interventions}

Similar as before, the exchange rate adjusts with respect to the excess demand

$$
P_{t+1}=P_{t}+a\left(D_{t}^{C}+D_{t}^{F}+D_{t}^{B}\right)
$$

The order of fundamental and technical traders are now given as

$D_{t}^{F}=b\left(F-P_{t}\right)$

and

$D_{t}^{C}=c\left(P_{t}-P_{t-1}\right)$

respectively. The central bank seeks to counter these orders (so that the excess demand decreases). Their interventions are thus determined by

$D_{t}^{B}=-\frac{b d}{1+d}\left(F-P_{t}\right)-\frac{c e}{1+e}\left(P_{t}-P_{t-1}\right)$.

Obviously, the first term on the right-hand side of (8) reduces the demand of the fundamentalists while the second term reduces the demand of the chartists. The parameters $d$ 
and $e$ are both positive.

Setting again $a=1$, the law of motion of the exchange rate becomes

$$
P_{t+1}+\left(\frac{b}{1+d}-\frac{c}{1+e}-1\right) P_{t}+\frac{c}{1+e} P_{t-1}=\frac{b}{1+d} F
$$

which still is a second-order linear difference equation.

It is straightforward to show that the fixed point $P_{t}=F$ is stable if $b /(1+d)>0$, $b<2+2 d+2 c(1+d) /(1+e)$, and $c<1+e$. What are the results? First, for $d=e=t a x$, the impact of central bank interventions is equal to the impact of transaction taxes. Second, as long as $0<e<d(1+c) /(c-d)$, central bank interventions increase the parameter space which guarantees stable exchange rate fluctuations. Third, the amplitude of the dynamics is independent of the parameter $d$. Note finally that for $d<0$ (which would imply amplifying the orders of the fundamentalists), the parameter space which yields stable dynamics decreases. $^{2}$

Since these results may appear somewhat surprising, let us try to clarify what is going on. Suppose that the exchange rate is above its fundamental value and increases further. In such a situation, chartists are buying and fundamentalists are selling. Using the intervention strategy (8), the central bank receives two contradictory signals so that their intervention volume remains relatively flat. At some time, however, the exchange rate returns towards its fundamental value. Then both chartists and fundamentalists are selling. Without any interventions (and also for $d<0$ ), the exchange rate would pick up momentum and drop below the fundamental value. But when the central bank counters the selling orders of both types of traders, this process is slowed down and the exchange rate path become more stable.

\footnotetext{
${ }^{2}$ Note that a strategy such as $D_{t}^{B}=-d\left(F-P_{t}\right)-e\left(P_{t}-P_{t-1}\right)$ may fail to increase the parameter space which yields stable motion. Central bank interventions thus have to be carefully designed.
} 


\section{Conclusions}

Professional market participants rely on both technical and fundamental trading rules when they determine their orders. A number of theoretical models have been proposed which show that interactions between chartists and fundamentalists are responsible for the high exchange rate variability observed empirically. One way to curb speculative activity may be to impose transaction taxes. Although there is some theoretical evidence that such a levy may indeed calm down financial markets, the introduction of transaction taxes currently seems not to be feasible. Our goal is to explore whether a similar stabilizing impact may be generated with carefully designed central bank interventions. As it turns out, we are able to show that interventions which counter the orders of both technical and fundamental traders have a similar effect on exchange rate dynamics as transaction taxes. Our results are based on a very stylized model. We hope, however, that this paper will stimulate more work in this exciting and important research area. 


\section{References}

Allen, H. and Taylor, M.(1990): Charts, noise, and fundamentals in the London foreign exchange market. Economic Journal, 100, 49-59.

Baumol, W. (1961): Pitfalls in contracyclical policies: Some tools and results. Review of Economics and Statistics, 43, 21-26.

Brock, W. and Hommes, C. (1998): Heterogeneous beliefs and routes to chaos in a simple asset pricing model. Journal of Economic Dynamics and Control, 22, 1235-1274.

Chiarella, C., Dieci, R. and He, X.-Z. (2006): Heterogeneous expectations and speculative behavior in a multi-asset dynamic framework. Journal of Economic Behavior and Organization (in press).

Day, R. and Huang, W. (1990): Bulls, bears and market sheep. Journal of Economic Behavior and Organization, 14, 299-329.

De Grauwe, P and Grimaldi, M. (2006): Exchange rate puzzles: A tale of switching attractors. European Economic Review, 50, 1-33.

Garber, P. and Taylor, M. (1995): Sand in the wheels of foreign exchange markets: A sceptical note. Economic Journal, 105, 173-180.

Haq, M., Kaul, I. and Grunberg, I. (1996): The Tobin Tax: Coping with Financial Volatility. Oxford University Press: New York.

Keynes, J.M. (1936): The General Theory of Employment, Interest, and Money. Harcourt Brace: New York.

Lui, Y.-H. and Mole, D. (1998): The use of fundamental and technical analysis by foreign exchange dealers: Hong Kong evidence. Journal of International Money and Finance, 17, $535-545$.

Lux, T. and Marchesi, M. (2000): Volatility clustering in financial markets: A microsimulation of interacting agents. International Journal of Theoretical and Applied Finance, 
3, 675-702.

Neely, C. (2001): The practice of central bank intervention: Looking under the hood. Federal Reserve Bank of St. Louis Review, 83, 1-10.

Rosser, J.B., Ahmed, E. and Hartmann, G. (2003): Volatility via social flaring. Journal of Economic Behavior and Organization, 50, 77-87.

Sarno, L. and Taylor, M. (2001): Official intervention in the foreign exchange market: Is it effective and, if so, how does it work? Journal of Economic Literature, 39, 839-868.

Taylor, M. and Allen, H. (1992): The use of technical analysis in the foreign exchange market. Journal of International Money and Finance, 11, 304-314.

Taylor, M. (2004): Is official exchange rate intervention effective? Economica, 71, 1-11.

Tobin, J. (1978): A proposal for international monetary reform. Eastern Economic Journal, 4, 153-159.

Westerhoff, F. (2004): Speculative dynamics, feedback traders and transaction taxes: A note. Review of Economics, 55, 190-195.

Westerhoff, F. and Dieci, R. (2006): The effectiveness of Keynes-Tobin transaction taxes when heterogeneous agents can trade in different markets: A behavioral finance approach. Journal of Economic Dynamics and Control, 30, 293-322. 